\title{
https://doi.org/10.46344/JBINO.2021.v10i2b.17
}

\section{A REVIEW ON ROLE OF YOGA IN VARIOUS DISEASES}

\section{'Dr. Hemantkumar Suresh Gautam, 2Dr. Vrushali Vasant Thote, ${ }^{3}$ Dr. Leena Ramraoji Zade}

\author{
'Reader, Department of Shalakyatantra, M.S. Ayurvedic College and Hospital, Gondia. \\ 2Reader, Department of Swasthavritta and Yoga, M.S. Ayurvedic College and Hospital, Gondia. \\ ${ }^{3}$ Reader, Department of Dravyaguna Vigyan, M.S. Ayurvedic College and Hospital, Gondia.
}

\begin{abstract}
Swastha is the state of maintaining equilibrium between Dosha, Dhatu and Mala with the proper functioning of Aatma, Indriya and Mana in the body. Yoga helps in connecting the mind with the body and soul. It consists of Asana, Pranayama and meditation. Asana is a particular position of the body which helps in achieving steadiness of body and mind. Pranayama helps in controlling breathing which is very effective than normal breathing. Meditation helps in connecting mind, body and soul. Yoga is found to be very effective in diseases like rhinitis, asthma, sinusitis, hearing loss, bronchitis etc. Yoga produces Nadi shuddhi (purification of all the channels) and Mala shuddhi (eradication of factors that disturb balanced working of body and mind) which help in enjoying positive health and freedom from diseases.
\end{abstract}

Key-word- Swastha, Asana, Yoga, Pranayama, Meditation, Disease. 


\section{Introduction}

Yoga is the ancient healing system of the India. The word 'Yoga' is derived from word "Yuj" which means 'union'. It helps in achieving a union and harmony between our mind, body and soul.[" It involves series of activities performed synchronously such as breathing exercise, relaxation, meditation, and physical exercise. It helps in achieving physical, mental, social and spiritual well-being. Yoga not only comprises of only breathing exercise, Asanas but it also consist of ethical codes and personal discipline necessary for ethical, spiritual and social development. The Asanas and Pranayam, improve the physical development and physical activity. Meditation helps in the inner union of our personal consciousness with inner peace. Yoga helps in achieving the state of complete physical, mental and social wellbeing. Pranayama is an ancient Indian practice of controlling one's breathing. It helps in relieving anxiety, depression; improve blood circulation and concentration. [2]

\section{Sinusitis}

Sinusitis is the inflammation of the sinuses. Sinuses are small, air filled spaces present behind the nose and facial bone. Sinuses open into the nose and help in the maintenance of temperature of the air which is reaching to the lungs. Sinus produces mucus which drains into the nose through small channels. Sinusitis can occur due to viral, bacterial, fungal, allergic infections. The inflammation of sinus leads to blockade of the normal drainage pathways, leading to mucus retention which causes difficulty in breathing, running nose, headache etc. [3]

Various symptoms of Sinusitis are Jwara (Fever), change in voice, nasal obstruction, purulent nasal discharge, headache etc. In case of chronic sinusitis, dull pain or pressure is experienced across the midface, nasal congestion etc.

Yoga is found to be very effective therapy in curing Sinusitis. It helps in balancing the Nadis (energy centers) in the body and removes the obstruction caused due to inflammation.

The chanting and humming of word "OM" helps in creating sound vibrations which allows movement of air between the sinus membrane and nasal passages.[4] This results in opening of channels connected to the nose therefore allowing the sinuses to drain properly. This create a healthy environment and reduction in the infection. [5]

> Gomukhasana (cow face pose) helps in stretching of chest muscles providing flexibility in the air passage region and reduces stress.

Janu Sirsasana (Head to knee pose) provides relief in headaches, insomnia.

Bhastrika Pranayama helps in removal of microbes, deoxygenated air therefore facilitating the drainage of the excess mucous from the sinuses.

$>$ Anulom Vilom Pranayama is also referred as Nadisodhana Pranayama. It helps in removing the congestion from the Nadis therefore maintain the free flow of energy and also improves the immune system.[6] 
$>$ Bhujangasana (cobra pose) stretches lungs therefore makes breathing easier.

$>$ Kapalabhati is of prime importance as it is the best exercise for cleaning respiratory blockages, improving mental functioning and refreshing the head region.

> Meditation and Mantra recitation improves the microcirculation which reduces the stress. Stress free mind is important for the healthy body and soul.[7]

Jala neti is the procedure of nasal irrigation by lukewarm saline water, which removes the dried mucous from the nose, cleanses sinuses and helps in restoring the flow of air. [8]

> Kunjal kriya helps in expulsion of phlegm and mucous deposited in the body.

\section{Chronic Rhinosinusitis}

Chronic rhinosinusitis is a common clinical condition these days affecting the general population due to improper Vihara, increased pollution, and increase in resistance to antibiotics. The treatment planning includes medications such as antihistaminics, nasal decongestants, and antibiotics. [9] But they have various side effects and can lead to antibiotic resistance. Some Yoga techniques such as Jal Neti, Bhramari pranayama is proven to be safe and effective in various clinical conditions of ear, nose, and throat.

Bhramari pranayama is a breathing exercise in which the patient is asked to take a deep breath and exhale slowly through his nose making a loud humming sound and focusing his attention on the areas between the eyebrows by keeping his eyes closed. It is observed in several studies that humming acts as a sonic cleanser.[10] It increases the generation of nitric oxide level to many fold and thus stimulates vaso-dilation. Thus increases the air conditioning and cilliary movement which results in better drainage of the nose and paranasal sinuses. [1]]

\section{Hearing loss}

Due to the increase in noise pollution, excessive usage of mobile phones; ototoxic drugs, the incidence of deafness is increasing. According to W.H.O. approximately, 360 million individuals in the world are suffering from hearing loss. There are many causes of deafness such as noise, hypertension, hypothyroidism, obesity, electromagnetic field, diabetes, cervical spondyliosis, sinusitis, etc.

Various Yoga Aasanas help in restricting the progressive hearing loss. Various neck muscles exercises and deep breathing exercises such as Kumbhak, helps in increasing the blood and oxygen supply to the inner ear.

Greeva chalan (neck exercise) such as Cervical or neck flexion extension exercise, Lateral flexion exercise and Head Rotation exercises. These Yogic exercises improve blood supply to brain and labyrinth.

Bhramari pranayama (bee breath) provides relief in tinnitus by stimulating the hair cells. This stimulation is done by neural reprogramming through sound generated by Bhramari Pranayama and Shanmukhi Pranayam. This produces vibration in the skull, brain and cochlea. The humming sound generates, echo in the ears.[12] The damage of hair cells in old age can be prevented by neural plasticity through Shankha Naad and Bhramari Pranayam.

$>$ Kumbhak is a respiratory exercise which is similar to Carbogen therapy given to treat 2021 April - May Special Edition | www.jbino.com | Innovative Association 
cerebral atrophy, deafness and Alzheimer's disease. In Kumbhak, we exhale the air for the maximum period which increases the carbon dioxide level in the blood. This stimulates the vasodilation, increases arterial oxygen concentration and the blood supply to the injured hair cells of cochlea which regenerate the hearing area. [13]

Shankhanaad is a powerful respiratory exercise of blowing a Shankha (snail pipe) which helps in toning of respiratory muscles. The sound produced by Shankhanaad stimulates the hair cells in inner ear thus prevent the hearing loss due to ageing. It also improves the vital capacity, speech defects, etc.

\section{Allergic rhinitis}

It is an allergic condition caused by various allergens or foreign particles. It is also termed as Hay fever, characterized by inflammation of the nasal passage, reddening of eyes, swelling, watery nose, sore throat, headache, sneezing, coughing and skin blisters. There are many Yoga Aasanas which improve breathing and immunizes the body against allergies.

Vrikshasana (Tree Pose) improves the spinal column and enhance the balance of the body. It improves blood circulation and also improves breathing.

> Salamba Sarvangasana (Shoulder-Stand Pose) is beneficial for the nerves and mind. It also reduces insomnia, irritability; improves blood flow in the lungs; boost immunity and provide relief from allergic rhinitis.

Veerabhadrasana (Warrior pose) improves respiration, balance in the body; relieve stress and increases blood circulation.
> Matsya Asana (Fish Pose) promotes deep breathing by stretching and strengthening the lung muscles. Thus improve circulation and distribution of blood throughout the body. It is essential in relieving allergic conditions and improving overall immunity.

\section{Asthma and Bronchitis}

Asthma is a common respiratory disease in which the bronchi (bronchi) gets narrowed which causes difficulty in breathing. The attack is characterized by sudden shortness of breath and wheezing, accompanied by a cough. Asthma attacks are triggered by infections such as colds and sinus infections, dust, food allergens, etc.

Bronchitis is a serious lung and bronchial infection caused due to inhalation of contaminated air, smoke; bacterial or viral infection. Asthma attacks occur most frequently in winter, humid climates, highly polluted environment, overcrowding, etc. Yoga helps in improving breathing, control mind and emotions. This increases the lungs function, airflow, relieve tension, increase flexibility and tone the respiratory muscles.

Sukhasana helps in balancing the spine, slow down metabolism and promotes inner peace.

> Shoulder Lifts improve stiffness, poor posture and tension headaches.

> Surya Namaskar is a sequence of twelve Yoga aasanas performed as a continuous exercise. It provides relaxation to the whole body.

$>$ Ardha Matsyendrasana helps in lengthening and strengthening of the spine. It is also advantageous for the liver, kidneys and adrenal glands. 
> Pavanmuktasana is mainly for the digestive system and helps in eliminating excess gas of the stomach.

$>$ Pranayama is the breathing control of inhalation, exhalation and the retention of vital energy.

Anuloma Viloma (three-part breathing): This is a three part breathing exercise. During an asthma attack, this method may be more beneficial as it encourage the maximal entry of oxygen into the body. According to scholars, Yoga helps in keeping body and mind relaxed. Breathing exercises during Yoga are found to be effective in improving lung function and therefore has a positive effect on the respiratory system. Pranayama is a wellregulated breathing in which the lungs expand more frequently during normal breathing this leads to an increase in the surface area and therefore improve the spreading capacity. Due to the improved breathing pattern, the bronchioles get widened, relaxes somatic muscles and thus exchange of air is carried out effectively. [14] Yoga increases respiratory capacity by increasing chest wall expansion and expiratory lung volume. [15] It also increase oxygen consumption by 15 to $25 \%$.[16]

\section{Conclusion}

Yoga helps in achieving physical, mental and spiritual relaxation. It includes intake of proper healthy diet, Yoga Asana, meditation, breathing exercises to accomplish the highest level of consciousness. Yoga has the potential to prevent progression of the disease and if started in the early phase, it may even provide the cure. Yoga aims to promote positive hygiene and health through development of inner powers of body and mind. It gives special attention to various eliminative processes and inherent powers of adaptation and adjustment of body and mind. Yoga produces Nadi shuddhi (purification of all channels of communication) and Mala shuddhi (eradication of factors that disturb balanced working of body and mind) which help in enjoying positive health and freedom from diseases.

\section{Discussion}

Ayurveda and Yoga therapy have become important part of life to rejuvenate the body for a better harmony in the mind, body and soul. It helps to maintain health, prevention from various diseases. Yoga includes the Aasanas, breathing and relaxation exercises to control the mind and emotions and making body more relaxed. It help lungs to work better and enhance oxygen saturation in cells. It also improve the function of other organs of the body and very helpful in removing the toxins from body that is very helpful to prevent from disorders like asthma, sinusitis, bronchitis, COPD etc. In the Yoga exercise there are a number of precise movements coupled with correct breathing techniques that have been known to play a very important role in improving the circulatory system. This helps in regenerating the hair cells of cochlea and thus improves the hearing ability in old age. Regular Pranayama (breathing exercises of various types), particularly alternate nostril breathing (Anulom vilom) and Kapalbhati have proven to be effective in asthma, head 
and neck problems, cardiovascular diseases, respiratory disorders, etc.

\section{Reference}

1. Shruti Agnihotri, Priyanka Gaur, Sandeep Bhattacharya, Surya Kant and Sarika Pandey. Benefits of Yoga in Respiratory Diseases. Indian J. Pharm. Biol. Res.2018; 6(4):10-13.

2. Gopal KS. Effect of yogasanas and pranayamas on blood pressure, pulse rate and some respiratory function. Indian Journal Physiol Pharmacol.1973; 73(3):27376.

3. Hodder Arnold (JAYPEE). Diseases of the Nose, throat and Ear, 1st ed. New Delhi: Jaypee Brothers Medical Publishers (P) Ltd;2007,47.

4. Bhavanani AB. Scientific Basis for some Yoga practices in sinusitis 2013,157.

5. Bauman, Alisa Sinusitis survival: Vibrations created from chanting $\mathrm{Om}$ can help clear your sinuses and ward off infections. Yog journal, Jan/Feb 2003.

6. Shirley Telles et.al., research paper, "Breathing through a particular nostril can alter metabolism and autonomic activities", Vivekananda Kendra Yoga Research Foundation, No.9 Appajappa Agrahara, Chamarajpet, Bangalore560018).

7. Krishna Bhat Dr., post graduate class notes on the topic "Basic principles of Yoga therapy".

8. Wankhede SD. Effect of ShuddhikriyaJalaneti in chronic sinusitis with special reference to JeernaPratishaya 2017.

9. Rudmik L, Soler ZM. Medical therapies for adult chronic sinusitis: A Systematic review. JAMA. 2015;314:926-39.
10. Bauman A. Sinusitis survival: Vibrations created from chanting Om can help clear your sinuses and ward off infections. Yoga J. 2003:3:34.

11. Maniscalo M. Humming, nitric oxide and paranasal sinuses ventilation. Eur Respir J. 2003;22:3239.

12. Martin L (2003) Lenhardt Ultrasonic hearing in humans, application for tinnitus treatment. Inttinnitus J 9: 69-75.

13. Lee HJ, Park CY, Lee JH, Yang HS, Kim $\mathrm{JH}$, et al. (2012) Therapeutic effects of carbogen inhalation and lipoprostaglandin El in sudden hearing loss. Yonsei Med J 53: 999-1004.

14. Goyeche, JRM., Abo, Y. andlkemi, Y. (1982). As thma: a perspective part 2: yoga therapy in the treatmentof asthma. J Asthma.19: 189-201.

15. Chanavirut, R., Khaidjapho, K., Jarce, P. andPongnaratorn, P. (2006). Yoga exercise increases chestwallexpans ion and lung volumes in young healthy thais. Thai Journal of Physiological Sciences. 19: 1-7.

16. Miles, WR. (1963). Oxygen consumption during the three type of breathing. J Appl Physiol.19(1):75-82. 